\title{
E-Therapy Autism Child with Multimedia Approach (EAMA) sebagai Intervensi Perubahan Psikomotor dan Afektif pada Anak Autis
}

\section{E-Therapy Autism Child with Multimedia Approach (EAMA) as an Intervention of Psychomotor and Afective Change in Autism Children}

\author{
Yena Wineini Migang ${ }^{1}$, Ferdinand Mahardhika ${ }^{2}$ \\ ${ }^{1}$ Poltekkes Kemenkes Palangka Raya \\ ${ }^{2}$ Universitas Bina Nusantara \\ (yenawineini.migang@yahoo.co.id)
}

\begin{abstract}
ABSTRAK
Autisme adalah gangguan otak pada perkembangan pervasif pada anak yang ditandai dengan adanya gangguan dan keterlambatan dalam bidang kognitif, imajinasi, bahasa, perilaku, komunikasi, dan interaksi sosial. Berdasarkan data Yayasan Autis Indonesia tahun 2013, di Kota Palangka Raya Kalimantan ada 250 ribu orang, 20\% diantaranya atau sekitar 50.000 adalah anak-anak dan diperkirakan 100 anak menderita autism. E-Therapy Autism Child with Multimedia Approach (EAMA) merupakan e-therapy yang diciptakan oleh peneliti, di dalamnya memuat juga unsur e-learning. EAMA berupa software aplikasi multimedia, gabungan dan pengembangan dari terapi autis metode Applied Behavioral Analysis (ABA) dan Treatment and Education of Autistic and Related Communication Handicapped Children (TEACCH). EAMA memfasilitasi intervensi untuk afektif, dan peningkatan kemampuan psikomotor. Penelitian dilakukan di Sekolah Khusus Melati Ceria (SKMC) Kota palangka Raya, jumlah sampel 30 orang, dengan total sampling. Desain eksperimen murni dengan one group pre and post test yang mengukur tingkat kemampuan psikomotor dan afektif anak autis, sebelum dan sesudah intervensi dengan aplikasi EAMA dirancang oleh peneliti. Uji analisis statistik dengan wilcoxon. Hasil penelitian menunjukkan tingkat psikomotor, sebelum dan sesudah diberi metode EAMA $(\mathrm{p}=0,000<0,05)$ dan $\mathrm{Z}(-4,899)$, maka ada pengaruh metode EAMA dengan tingkat psikomotor sebelum dan sesudah pemberian metode EAMA. Pada tingkat afektif, diperoleh nilai $(p=0,000<0,05)$ dengan nilai $Z=-5,292$, ada pengaruh pemberian metode EAMA dengan peningkatan nilai afektif pada anak autism.
\end{abstract}

Kata kunci : E-therapy, multimedia, autis, psikomotor, afektif

\section{ABSTRACT}

Autism is a brain disorder of pervasive development in children characterized by disturbances and delays in the fields of cognitive, imagination, language, behavior, communication, and social interaction. Based on data from the Indonesian Autism Foundation in 2013, there are 250 thousand people in Palangka Raya City, 20\% of them or around 50,000 are children and an estimated 100 children of autism. E-Therapy Autism Child with Multimedia Approach (EAMA) is an e-therapy created by researchers, which includes elements of e-learning. EAMA is a multimedia application software, a combination and development of autistic therapy method of Applied Behavioral Analysis (ABA) and Treatment and education of autistic and Handicapped Children Related Communication (TEACCH). EAMA's target target is children with autism to improve optimally cognitive, psychomotor and affective in children with autism. EAMA facilitates interventions for behavior change, and enhances psychomotor abilities. In children with autism they are easier to receive information through audio visual. EAMA is a multimedia that can help parents at home while with autism children as an exercise, and also as a learning method for autism teachers in school while teaching. After EAMA then accompanied by practice or simulation on this part as an evaluation of the increase in the ability of autism children. This research was conducted at Sekolah Khusus Melati Ceria (SKMC), Palangka Raya City, 30 people as samples, with total sampling. Experimental design with one group pre and post test, which measures the level of psychomotor and affective abilities of autism children, before and with an intervention with the application designed by the researcher, namely EAMA. Statistical analysis test with Wilcoxon. Research Results: Psychomotor level, before and after given the EAMA method $\rho(0,000)<0,05$ and $Z(-4,899)$, then there is the influence of EAMA method with psychomotor level before and after giving EAMA method. At the affective level, the value of $\rho(0,000)<0,05$ with a value of $Z(Z-5,292$, there is an effect of giving EAMA methods with an increase in affective value in children with autism.

Keywords : E-therapy, multimedia, autism, psychomotor, affective 


\section{PENDAHULUAN}

Autisme adalah gangguan otak pada perkembangan pervasif pada anak yang ditandai dengan adanya gangguan dan keterlambatan dalam bidang kognitif, imajinasi, bahasa, perilaku, komunikasi, dan interaksi sosial. ${ }^{1}$ Gangguan autis menyerang bagian otak kecil yang memproduksi hormon, hal ini menyebabkan ketidakseimbangan neuro transmitter serotonin. Akibatnya transmisi pesan dari satu neuron ke neuron lain terhambat. Indra persepsi penyandang autis berfungsi dengan baik, tetapi rangsangan yang ditangkap tidak dapat diproses dengan baik, hal ini menyebabkan anak autis hidup di dunianya sendiri. Autisme tidak dapat disembuhkan (not curable), tetapi dapat diterapi (treatable). ${ }^{2}$

Center for Disease Control and Prevention (CDC) memperkirakan bahwa 1 dari 68 anak-anak (atau 14,7 per 1.000 delapan tahun) di beberapa komunitas di Amerika Serikat telah diidentifikasi dengan Autism Spectrum Disorder (ASD). Perhitungan tersebut $30 \%$ lebih tinggi dari yang dilaporkan pada tahun 2012, terdapat 1 dari 88 anak (11,3 per 1.000 delapan tahun) diidentifikasi dengan ASD. Jumlah anak-anak yang diidentifikasi dengan ASD di Alabama, berkisar 1 dari 175 dan di New Jersey diperkirakan 1 dari 45 anak-anak. Prevalensi ASD hampir lima kali lebih banyak pada anak laki-laki dibandingkan anak perempuan dengan perbandingan 1 dari 42 anak laki-laki dan 1 dari 189 perempuan. Anak putih lebih cenderung diidentifikasi sebagai memiliki ASD daripada anak-anak kulit hitam atau Hispanik. ${ }^{3}$

Belum ada survei resmi di Indonesia tentang data anak autis, tahun 2013 Direktur Bina Kesehatan Jiwa Kementerian Kesehatan menduga jumlah anak autis di Indonesia sekitar 112 ribu dengan rentang usia 5-19 tahun. Angka ini keluar berdasarkan hitungan prevalensi autis sebesar 1,68 per 1000 anak di bawah 15 tahun. Dengan jumlah anak usia 5-19 tahun di Indonesia sejumlah sekitar 66 juta. Berdasarkan uraian dari Yayasan Autisma Indonesia, sepuluh tahun lalu jumlah penduduk di Palangka Raya, Kalimantan Tengah, ada 250 ribu orang, 20\% diantaranya atau sekitar 50.000 adalah anak-anak. Pada saat itu diperkirakan ada 100 anak Autis di dalamnya. Ada kecenderungan kasus autis terus meningkat.

Secara umum anak autis memiliki kemam- puan yang menonjol di bidang visual. Mereka lebih mudah untuk mengingat dan belajar, apabila diperlihatkan gambar atau tulisan dari benda, kejadian, tingkah laku maupun konsep-konsep abstrak. Melihat gambar atau tulisan, anak autis akan membentuk gambaran mental yang jelas dan relatif permanen dalam benaknya. Apabila materi tersebut hanya diucapkan saja, akan mudah melupakannya karena daya ingat yang amat terbatas. Oleh karena itu, dalam melakukan terapi digunakan sebanyak mungkin kartu-kartu bergambar dan alat bantu visual lain untuk membantu mengingat, hal ini juga berlaku untuk anak autis yang hanya mengalami gangguan di bidang verbal. ${ }^{4}$

E-Therapy Autism Child with Multimedia Approach (EAMA) merupakan e-therapy yang di dalamnya memuat juga unsur e-learning. EAMA berupa software aplikasi multimedia, gabungan dan pengembangan dari terapi autis metode $A p$ plied behavioral Analysis (ABA) dan Treatment and education of autistic and Related Communication handicapped Children (TEACCH), yang merupakan media memuat audio dan visual mempermudah anak autis mengingat. Berdasarkan hal tersebut maka peneliti mengembangkan EAMA sebagai e-therapy untuk mengatasi masalah pada gangguan kognitif, psikomotor dan afektif. Salah satu yang diamati adalah perubahan perilaku dan kemampuan motorik untuk aktivitas sehari-hari.

\section{BAHAN DAN METODE}

Rancangan penelitian ini adalah desain eksperimen murni dengan one group pre dan post test yang bertujuan mencari pengaruh EAMA pada anak autis dengan melihat nilai kemampuan psikomotor dan afektif anak autis, sebelum dan sesudah mendapat intervensi dengan EAMA. EAMA adalah sebuah aplikasi multimedia yang dirancang oleh peneliti sebagai media untuk pembelajaran pada anak autis. Lokasi penelitian di Sekolah Khusus Melati Ceria (SKMC) Palangka Raya. Subyek penelitian adalah anak autis di mulai bulan Mei sampai dengan November 2017. Sampel pada penelitian ini adalah 30 anak autis, yang merupakan jumlah anak yang masih terdaftar aktif di SKMC, Kota Palangka Raya. Penelitian ini menggunakan total sampling, yakni semua anak yang didiagnosa autis pada SKMC Kota Palangka Raya.

Metode pengumpulan data yang digunakan 
dalam penelitian ini adalah menggunakan 1 (satu) group dengan jenis data primer, data diambil berdasarkan instrumen penilaian dari SKMC untuk mengukur kemampuan kognitif dan afektif anak autis. Sebelum diberi intervensi dengan EAMA, terlebih dahulu dilakukan pengukuran kemampuan psikomotor dan afektif anak autis, dengan lembar ceklist. Kemudian intervensi dengan EAMA diberikan selama 4 minggu. Setiap anak diberikan perlakuan selama 15 menit setiap pertemuan. Pertemuan dilakukan berselang-seling sebanyak 3 kali dalam 1 minggu. Hari ke 20 akan dilakukan pengukuran kembali kemampuan psikomotor dan afektif anak autis. Sebelum penelitian dilakukan peneliti berdasarkan ethical clearance dan inform consent yang telah di tandatangani orang tua sampel. Variabel penelitian pada penelitian ini yaitu: (a) variabel independen (bebas) : $E$ Therapy Autism Child with Multimedia Approach (EAMA) (b) variabel dependen (terikat) : Tingkat psikomotor anak autis dan tingkat afektif anak autis. Analisa univariat, memeriksa variabel secara deskriptif yang berskala ordinal dengan tabel distribusi frekuensi. Analisa bivariat pada penelitian ini untuk mengetahui pengaruh intervensi EAMA. Maka pada satu group yang sama, nilai sebelum dan sesudah tingkat psikomotor dan afektif. Maka uji analisis yang digunakan dengan Wilcoxon, dengan variabel kontrolnya adalah lamanya terapi di SKMC, penerapan diet bebas glutein dan kasein oleh orangtua.

\section{HASIL}

Penelitian dilakukan dari bulan Mei 2017 sampai dengan November 2017, di SKMC Palangka Raya, sampel yang digunakan berjumlah 30 anak autis dengan karakteristik telah mampu kooperatif saat proses pembelajaran, dan tidak mengalami cacat fisik. Sebanyak $93,3 \%$ responden berjenis kelamin laki-laki, $86,7 \%$ berusia $5-10$ tahun. Sebagian besar responden $(90,0 \%)$ melakukan diet bebas glutein dan kasien. Berdasarkan lama terapi diperoleh informasi bahwa $86,7 \%$ anak autis telah diterapi $>1$ tahun di SKMC (Tabel 1). Berdasarkan Tabel 2 sebelum diberikan perlakuan dengan aplikasi EAMA, tingkat psikomotor 30 sampel anak autis sebanyak $4(13,3 \%)$ orang untuk melaksanakan aktivitas rutin sehari-hari dari bangun tidur sampai pergi ke sekolah, sesuai yang
Tabel 1. Karakteristik Sampel Anak Autis

\begin{tabular}{lcc}
\hline \multicolumn{1}{c}{ Karakteristik } & $\mathbf{n}$ & $\mathbf{\%}$ \\
\hline Jenis kelamin & & \\
$\quad$ Laki-laki & 28 & 93,3 \\
$\quad$ Perempuan & 2 & 6,7 \\
Usia & & \\
$\quad$ 5-10 tahun & 26 & 86,7 \\
$\quad$ 11-15 tahun & 4 & 13,3 \\
Diet bebas glutein dan kasein & & \\
$\quad$ Diet & 27 & 90,0 \\
$\quad$ Tidak diet & 3 & 10,0 \\
Lama Terapi di SKMC & & \\
$\quad>1$ tahun & 26 & 86,7 \\
$\quad \leq 1$ tahun & 4 & 13,3 \\
Pendidikan Ibu & & \\
$\quad$ SMP & 2 & 6,7 \\
$\quad$ SMA & 12 & 40,0 \\
$\quad$ PT & 16 & 53,3 \\
\hline
\end{tabular}

ada di aplikasi, memerlukan bantuan penuh orang lain, $24(80 \%)$ orang dengan bantuan melakukan aktivitas rutin dan $6(6,7 \%)$ orang tanpa bantuan dalam melakukan aktivitas. Setelah diberikan perlakukan dengan EAMA, tanpa bantuan meningkat menjadi $24(80 \%)$, sedangkan yang bantuan penuh tinggal $2(6,7 \%)$, dan dengan bantuan menurun menjadi $4(13,3 \%)$.

Berdasarkan Tabel 3, tingkat afektif sesudah dan sebelum perlakuan dengan metode EAMA. Sebelum diberi perlakuan dengan EAMA, tingkat afektif negatif 5 (16\%) orang, afektif apatis 25 $(83,3 \%)$ orang dan afektif positif tidak ada $(0 \%)$, setelah diberi perlakukan EAMA maka afektif negatif berkurang menjadi $2(6,7 \%)$ orang, afektif negatif $3(10 \%)$ orang dan afeksi positif menjadi $25(83,3 \%)$ orang. Dengan $\mathrm{p}(0,000)<0,05$ dan $\mathrm{Z}$ $(-4,899)$, maka ada pengaruh metode EAMA dengan tingkat psikomotor sebelum dan sesudah pemberian metode EAMA. Variabel tingkat afektif pada anak autis sebelum dan sesudah pemberian metode EAMA, menunjukkan hasil uji analisis nilai $p(0,000)<0,05$ dengan nilai $Z(Z-5,292)$ yang berarti ada pengaruh pemberian metode EAMA dengan peningkatan nilai afektif pada anak autis.

\section{PEMBAHASAN}

Hasil pada penelitian ini menunjukkan bahwa ada pengaruh pemberian metode EAMA dengan tingkat psikomotor dan tingkat afektif pada anak autism. Metode EAMA adalah konsep bela- 
Tabel 2. Tingkat Psikomotor dan Afektif Anak Autis

\begin{tabular}{lcccc}
\hline & \multicolumn{2}{c}{ Vebelum EAMA } & \multicolumn{2}{c}{ Sesudah EAMA } \\
\cline { 2 - 5 } & $\mathbf{n}$ & $\mathbf{\%}$ & $\mathbf{n}$ & $\mathbf{\%}$ \\
\hline Tingkat Psikomotor & & & & \\
$\quad$ Bantuan penuh & 4 & 13,3 & 2 & 6,7 \\
$\quad$ Dengan bantuan & 24 & 80 & 4 & 13,3 \\
$\quad$ Tanpa bantuan & 2 & 6,7 & 24 & 80 \\
Tingkat Afektif & & & & \\
$\quad$ Negatif & 5 & 16 & 2 & 6,7 \\
Apatis & 25 & 83,3 & 3 & 10 \\
$\quad$ Positif & 0 & 0 & 25 & 83,3 \\
\hline
\end{tabular}

Tabel 3. Analisa Pengaruh Metode EAMA dengan Tingkat Psikomotor dan Afektif pada Anak Autis

\begin{tabular}{lcccc}
\hline \multicolumn{2}{c}{ Variabel Penelitian } & n & Mean Rank & Hasil Uji Statistik \\
\hline Psikomotor sesudah & Negative Ranks & $0^{\mathrm{a}}$ & 0,00 & Z -4,899b \\
Psikomotor sebelum & Positive Ranks & $24^{\mathrm{b}}$ & 12,50 & Asymp. Sig. (2-tailed) \\
& Ties & $6^{\mathrm{c}}$ & & 0,000 \\
& Total & 30 & & \\
& & & & \\
Afektif sesudah & Negative Ranks & $0^{\mathrm{d}}$ & 0,00 & Z -5,292b \\
Afektif sebelum & Positive Ranks & $28^{\mathrm{e}}$ & 14,50 & Asymp. Sig. (2-tailed) \\
& Ties & $2^{\mathrm{f}}$ & & 0,000 \\
& Total & 30 & & \\
\hline
\end{tabular}

jar dengan multimedia untuk anak autis. Penelitian ini menggunakan metode EAMA, didalamnya terdapat video yang animasi lagu berisi tentang rangkaian kegiatan, kemudian rangkaian kegiatan tersebut dibuat menjadi puzzle, yang dibuat game agar anak autis menyenangi untuk mengingat urutan kegiatan rutin tersebut. Puzzle merupakan jenis gamifikasi, yang merupakan permainan yang bisa memberi stimulasi motivasi bagi anak untuk mengikuti seperti yang ada pada game tersebut, sehingga bisa menjadi terapi untuk peningkatan psikomotor dan perubahan perilaku. ${ }^{1}$

Menurut Kurdi, gejala seperti kurang inisiatif, hiperaktivitas, gangguan tidur dan gangguan makan terjadi pada anak autis usia 0-12 bulan, tetapi tidak menutup kemungkinan terjadi juga pada masa usia pra sekolah dan sekolah, tetapi gejala ini tidak terlalu spesifik. Kurangnya inisiatif dalam melakukan kegiatan yang memiliki tujuan membuat anak autis menolak untuk diajarkan berbagai kegiatan rutinitas karena cenderung menyenangi kegiatan yang hanya mereka anggap menyenangkan. ${ }^{5}$

Aplikasi EAMA saat diberikan pada anak autis merupakan game yang menyenangkan, sampel saat diminta untuk mengulang kembali kegiatan tersebut melakukan tanpa bantuan orangtua, mereka mampu untuk mengerjakannya dengan senang hati dengan mengikuti gambar atau video dalam aplikasi. Sebelumnya tingkat psikomotor tanpa bantuan persentasenya hanya $6,7 \%$ meningkat menjadi $80 \%$. Walaupun tidak sepenuhnya orangtua melepas anak-anak mereka dalam melakukan aktivitas ini. Masih ada 6,7\% tingkat psikomotornya dengan bantuan penuh dan 13,3 \% dengan bantuan, hal ini disebabkan tingkat koordinasi yang kurang pada responden. Responden tidak dapat melakukan komunikasi, sehingga mengganggu proses penyampaian pesan edukasi lewat multimedia aplikasi EAMA.

Umumnya terapi untuk menangani gangguan perilaku anak autis dilakukan dengan menggunakan model Applied Behaviour Analysis (ABA). Model ini dapat membimbing anak autis gangguan perilaku agar patuh (bukan takut) dan kreatif. Ada beberapa prinsip terapi perilaku model ABA. Penatalaksananan terapi dilakukan secara terstruktur. Terapis menggunakan teknik terapi secara ter- 
program dengan jelas. Dalam kegiatan intervensi pelaksananan program terarah. Panduan program yang dibuat oleh terapis digunakan sebagai acuan terapi. Penatalaksanaan terapi dilakukan secara terukur, dapat diketahui keberhasilan atau kegagalan dengan pasti. Tingkat pecapaian program terapi dapat diukur berdasarkan kriteria yang disusun oleh terapis. $^{6}$

Aplikasi EAMA di dalamnya memuat intervensi perubahan perilaku dengan metode $\mathrm{ABA}$. Mencakup permainan yang memberi instruksi dengan suara, permainan tersebut memberi pilihan kepada sampel, untuk menentukan pilihan sikap, yakni membuang sampah pada tempatnya atau tidak, dan pilihan mencuci tangan sebelum makan, jika pilihan tepat maka akan ada suara pujian yang diberikan kepada anak autis. Berdasarkan penelitian Schuetze et al., pemberian pujian merupakan salah satu intervensi yang sangat menyenangkan dan menstimulasi bagi anak autis dengan memberikan pengaruh terhadap respon psikologi. ${ }^{7}$

Pujian yang diberikan pada sampel saat benar menentukan sikap yang tepat, maka akan ada pujian, pujian inilah yang diharapkan dapat me- rubah perilaku anak. Pujian membuat anak ingin mengulang lagi kejadian tersebut karena menganggap pujian adalah sesuatu yang menyenangkan. ${ }^{8}$ Pada penelitian ini, sebanyak $83,3 \%$ tidak peduli bahwa membuang sampah harus mencari bak sampah terlebih dahulu, kemudian sampah dibuang. Namun, setelah diberikan terapi metode EAMA maka $83,3 \%$ menjadi sikap positif, yakni mengerti dan mau melakukan membuang sampah pada tempatnya. Walaupun masih ada $10 \%$ yang masih apatis, hal tersebut dikarenakan tingkat konsentrasi sampel sangat rendah untuk mengikuti metode EAMA seperti yang diajarkan.

Pada penelitian ini menyatakan tingkat psikomotor, sebelum dan sesudah diberi metode EAMA $p(0,000)<0,05$ dan Z $(-4,899)$ ' menyatakan ada pengaruh metode EAMA dengan tingkat psikomotor. Hasil uji tingkat afektif analisis didapati nilai $p(0,000)<0,05$ dengan nilai $Z(Z-5,292)$ yang berarti ada pengaruh pemberian metode EAMA dengan peningkatan nilai afektif pada anak autis. Sejalan dengan hasil penelitian Lokhorst, mengatakan game merupakan sarana yang bisa merubah perilaku. ${ }^{9}$ Metode dengan melibatkan multimedia, dapat menyebabkan penyembuhan kerusakan sistem saraf yang dapat mempengaruhi perilaku, salah satu perilaku yang diharapkan adalah melakukan kegiatan rutin sehari-hari dengan menentukan sikap yang benar saat menentukan dua pilihan sikap. ${ }^{10}$ Studi Postel ${ }^{10}$ yang melakukan kajian untuk menilai kelayakan intervensi kelompok CBT selama 8 minggu untuk mengatur sendiri kesulitan pemrosesan sensorik. Penelitian tersebut dilakukan pada remaja, dengan kognitif yang didiagnosis dengan autis berusia 11-16 tahun dari satu sekolah menengah umum mendapat intervensi 8 minggu. Tindakan reaktivitas sensorik, kecemasan dan perilaku berulang dilakukan pada awal, pasca intervensi dan tindak lanjut, 8 minggu setelah intervensi dihentikan. Wawancara semi terstruktur dan kelompok fokus juga dilakukan dengan remaja dan orang tua mereka untuk memeriksa lebih lanjut penerimaan intervensi. Hasil penelitian Postel menunjukkan bahwa intervensi dapat diterima baik dalam penerapannya maupun penerimaannya oleh responden. ${ }^{10}$ Analisis kualitatif dengan jelas menunjukkan bahwa intervensi tersebut efektif dalam meningkatkan kesadaran dan pengaturan diri secara sadar. Multimedia merupakan salah satu sarana untuk dapat melakukan edukasi pada anak autis. Anak autism sangat menyenangi halhal yang bersifat audio visual. ${ }^{11}$ Terapi visual, bertujuan agar anak-anak autis dapat belajar dan berkomunikasi dengan cara melihat (visual learner) gambar-gambar yang unik dan disenangi misalnya dengan metode Picture Exchange Communication System (PECS). ${ }^{12}$

Terapi musik dapat juga dilakukan untuk membantu perkembangan anak. Musik yang dipakai adalah musik yang lembut, dan dapat dengan mudah dipahami anak. Tujuan dari terapi musik ini adalah agar anak dapat menanggap melalui pendengarnnya, lalu diaktifkan di dalam otaknya, kemudian dihubungkan ke pusat-pusat saraf yang berkaitan dengan emosi, imajinasi dan ketenangan. ${ }^{10}$ Perpaduan antara terapi visual, musik dan dikombinasi dengan pujian untuk pilihan perilaku yang tepat dapat dipadukan dengan permainan, terapi ini meningkatkan pengetahuan anak autis sehingga adanya perubahan perilaku dan keinginan untuk melakukan. ${ }^{13}$ EAMA menggabungkan semua unsur visual, audio, ada pujian dan musik yang menyenangkan, anak autis akan diajak dalam permainan untuk menentukan sikap yang benar, 
dan dituntut melakukan tanpa paksaan. Pembelajaran secara konvensional dengan penjelasan secara verbal oleh terapis, guru atau orangtua cenderung membosankan bagi anak autis dan tidak dapat meningkatkan kemampuan komunikasi, perubahan perilaku. Hal ini sejalan dengan penelitian Tien tentang efektivitas Picture Exchange Communication System (PECS) untuk meningkatkan keterampilan komunikasi fungsional individu dengan gangguan spektrum autisme (ASD). Intervensi yang efektif selain memberi pengaruh perubahan psikomotor dan afektif juga meningkatkan keterampilan komunikasi secara fungsional. ${ }^{15}$

\section{KESIMPULAN DAN SARAN}

Berdasarkan hasil penelitian yang dilakukan di SKMC Palangka Raya, dari bulan Mei 2017 sampai dengan bulan November 2017. Ada pengaruh pemberian metode EAMA dengan tingkat psikomotor dan afektif pada anak autis. Tingkat psikomotor, dengan metode EAMA $\mathrm{p}(0,000)<0,05$ dan nilai $Z(4,899)$, dan tingkat afektif, $p(0,000)<0,05$ dengan nilai $Z(Z-5,292)$.

Saran dari penelitian ini, yaitu perlu ada stimulasi edukasi multimedia yang dapat membantu anak autis untuk melakukan aktivitas dan merubah perilaku yang negatif menjadi positif, perlu dikembangkan metode multimedia yang dapat menstimulasi tumbuh kembang dan dapat mengukur perkembangannya, perlu adanya peran orang tua dalam mendampingi anak saat bermain game edukasi, agar sasaran dari aplikasi permainan tersebut dapat tercapai dan perlu penelitian lanjut lagi untuk menyempurnakan aplikasi EAMA sebagai sarana edukasi.

\section{UCAPAN TERIMA KASIH}

Terima kasih peneliti ucapkan kepada Badan Pengembangan Sumber Daya Manusia (BPSDM) Kesehatan Kemenkes RI, melalui Poltekkes Kemenkes Palangka Raya, yang sudah memberikan dukungan dana, sehingga penelitian ini dapat berjalan lancar. Kepada Sekolah Khusus Melati Ceria (SKMC) yang sudah berkenan bekerjasama untuk melaksanakan penelitian ini. Ucapan terima kasih juga diberikan kepada seluruh responden dan orang tua yang telah membantu dalam proses mengambil data serta semua pihak yang terlibat dalam proses penelitian ini.

\section{DAFTAR PUSTAKA}

1. Adly H, Noor M, Shahbodin F, Pee NC. Serious Game for Autism Children : Review of Literature. 2012;6(4):554-9.

2. Koegel L, Matos-fredeen R, Lang R, Koegel R. Interventions for Children with $\mathrm{Au}$ tism Spectrum Disorders in Inclusive School Settings. Cogn Behav Pract [Internet]. 2011; Available from: http://dx.doi.org/10.1016/j. cbpra. 2010.11.003.

3. (CDC) TC for DC and P. CDC Estimates 1 in 68 Children has been Identified with Autism Spectrum Disorder [Internet]. United State; 2014. Available from: https://www.cdc.gov/ media/releases/2014/p0327-autism-spectrum-disorder.html.

4. Boyd BA, Mcdonough SG, Bodfish JW. NIH Public Access. 2013;42(6):1236-48.

5. Kurdi FN. Strategi dan teknik pembelajaran pada anak dengan autisme. Forum Kependidikan,. 2009; 29(1).

6. Prasetyoningsih SA. Pengembangan Tindak Bahasa Terapi dalam Intervensi Anak Autis Spektrum Perilaku. Litera. 2016;15:120-7.

7. Schuetze M, Rohr CS, Dewey D, McCrimmon A, Bray S. Reinforcement Learning in Autism Spectrum Disorder. Front Psychol. 2017.

8. Inclusive Directions Flinders Therapy House. Early Intensive Behavioural Intervention Using the Principles of Applied Behavioural Analysis (ABA ). 2011.

9. Lokhorst S. The Use of Gamification in Interventions for Children with Autism. University of Twente; 2014.

10. Edgington L, Hill V, Pellicano E. Research in Developmental Disabilities the Design and Implementation of a CBT-Based Intervention for Sensory Processing Difficulties in Adolescents on the Autism Spectrum. Res Dev Disabil. 2016;59:221-33.

11. Postel MG, Haan MSHA De, Jong MDCAJ De, Ph D. E-Therapy for Mental Health Problems : Telemed E-Health. 2008;14(7):707-14.

12. Omar S, Bidin A. The Impact of Multimedia Graphic and Text with Autistic Learners in Reading. Univers J Educ Res. 2015;3(12):98996.

13. Kandaswamy R. iMedPub Journals The Neurological Damage Caused by Repetitive Be- 
havior Modification Based Therapies in $\mathrm{Au}-$ tism and the Myth of "Early Intensive Intervention" in Autism The Myth of "Early Intervention" in Autism with "Intensive " Methods and Applicatio. 2016;2-4.
14. Tien K. Effectiveness of the Picture Exchange Communication System as a Functional Communication Intervention for Individuals with Autism Spectrum Disorders : A Practice-Based Research Synthesis. 2008;43(1):61-76. 